\title{
Fabrication and Analysis of Mechanical Properties of Metal Matrix Nano Composite using Magnesium and CNT as the Blending Material
}

\author{
B. M. Swami Punniakodi \\ Faculty of Mechanical Engineering, Sri Muthukumaran Institute of Technology, Chennai, Tamil Nadu, India
}

\begin{abstract}
How to cite this paper: B. M. Swami Punniakodi "Fabrication and Analysis of Mechanical Properties of Metal Matrix Nano Composite using Magnesium and CNT as the Blending Material" Published in International Journal of Trend in Scientific Research and Development (ijtsrd), ISSN: 24566470, Volume-3 Issue-3 , April 2019, pp.185-189, URL: http://www.ijtsrd.co $\mathrm{m} /$ papers/ijtsrd217 21.pdf

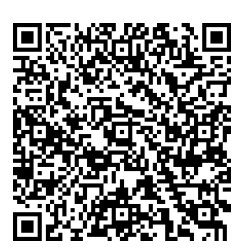

IITSRD21721
\end{abstract}

Copyright (C) 2019 by author(s) and International Journal of Trend in Scientific Research and Development Journal. This is an Open Access article distributed under the terms of the Creative Commons

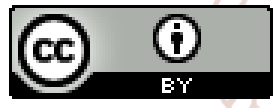
Attribution License (CC BY 4.0) (http://creativecommons.org/licenses/ by $/ 4.0$ )

\section{INTRODUCTION}

In recent years due to the evolution of composites in industry there is a drastic improvement in application of composite in industry. Nano composites play a vital role in the field of composites due to its varying properties according to the working environment. The nano composites have varying properties in mechanical, electrical and also the thermal conductivity of the material made of nano particles varies to increase its application in the desired environment. This property coupled with light weight makes these metal matrix nano composites an ideal material for the fabrication of many components involving hardness, tensile strength, wear strength and also other desired mechanical properties. Composite is a mixture of two materials which has different chemical and mechanical properties fabricated to make a material with superior property than that of the parent material. Its main property is high strength to weight ratio.

This project deals with fabrication of MMC with magnesium as the matrix and carbon nano tubes as the reinforcement. The reinforcement makes the metal much stronger and its blending with the matrix of magnesium leads to the even distribution of load acting on a composite. The fabrication technique applied here is sintering process where the carbon nano tubes along with the magnesium powder are mixed to the requirement and a solid composite is formed by the application of sintering process.

\section{Methodology}

The methodology used in fabricating these metal matrix nano composites is shown below.

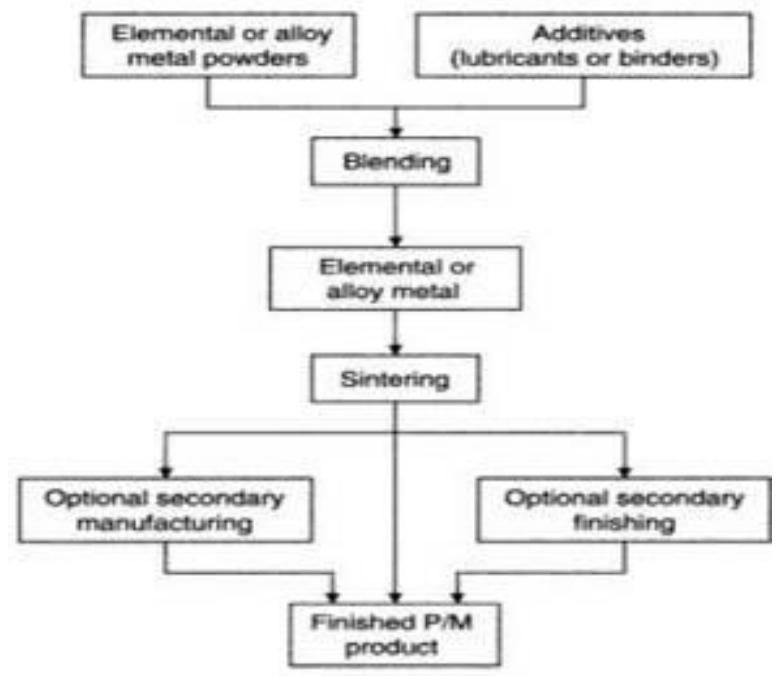


The carbon nano tubes are acquired according to the requirement of fabrication and the sintering technique is followed to fabricate the required metal matrix nano composite. The carbon nano tubes along with the magnesium were used as a fibre and matrix. The mixture is made to obtain the desired property of the composite. The fibre in nano form along with the matrix is allowed to cure and the curing period will be generally one day to set the fibre matrix interface. After curing is done it is cut to the required shape for the testing to takes place.

\section{Results and discussions}

\subsection{Vickers microhardness and tensile test:}

The ASTM guidelines were followed for preparing the tensile (E8M-04) and micro hardness (E384-99E1) specimens. The micro hardness specimens were loaded at the rate of 1.5 $\mathrm{kN} / \mathrm{min}$ in the advanced Vicker's micro hardness tester (Model:HMV-T1, Make: SHIMADZU) which is measured with $0.5 \mathrm{~kg}$ load at $15 \mathrm{sec}$ dwell time and at this condition, the readings were noted. Then, in order to find out the tensile strength of the fabricated composites, the prepared specimens were loaded at the rate of $1.5 \mathrm{kN} / \mathrm{min}$ in the electromechanical controlled UTM (Model: Instron-UNITEK94100; Cap. 0-100KN; Make: FIE-Blue Star) tester.

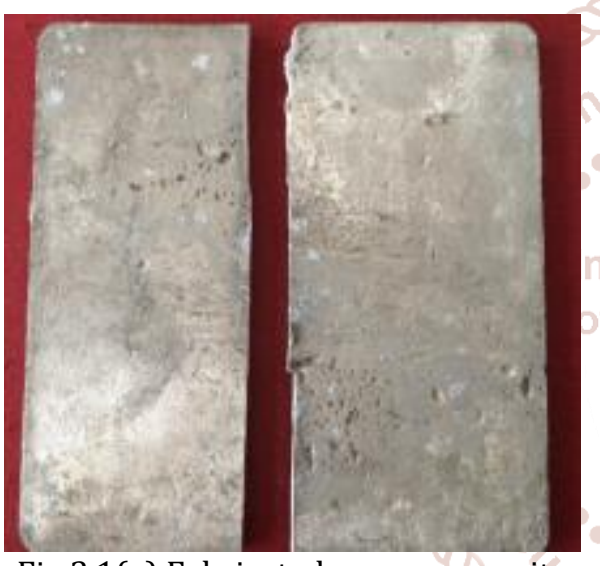

Fig 3.1(a) Fabricated nano composite

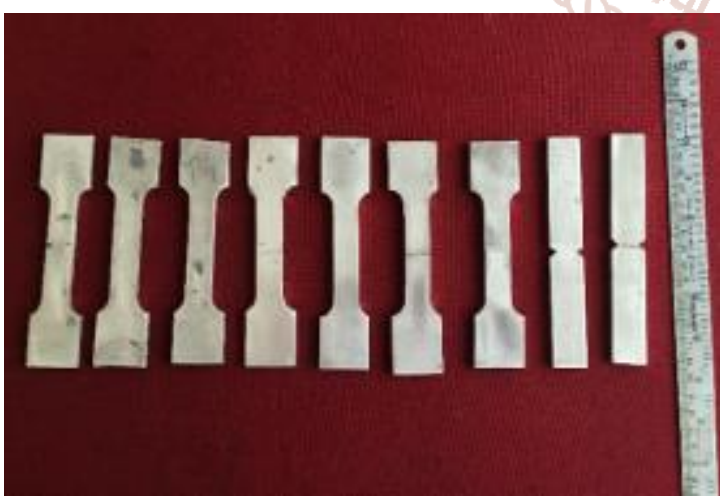

Fig 3.1(b) Tensile test specimen

\subsection{Wear test}

The pin-on-disc testing machine was used to perform the testing ambient temperature with the help of AISI 1040 grade medium carbon steel disc which has a specification of $10 \mathrm{~mm}$ in thickness and $55 \mathrm{~mm}$ in diameter. The pin having $40 \mathrm{~mm}$ in vertical height and $8 \mathrm{~mm}$ in diameter specimens was prepared to study the wear rate of the produced MMCs. The tests were taken on metal matrix nano composite specimen and it was conducted in dry sliding condition in three various loads such as $10 \mathrm{~N}(1 \mathrm{kgf}), 15 \mathrm{~N}(1.5 \mathrm{kgf})$ and $20 \mathrm{~N}$ (2kgf) for whole sliding distance of $1500 \mathrm{~m}$ at a disc speed of $650 \mathrm{rpm}$ which is constant for all specimens. The linear variable differential transformer was utilized for measuring the length (displacement) of the material at a good accuracy rate. The reduction in height is considered as wear rate of the samples. The coefficient of friction was also recorded while the experiments are being conducted.

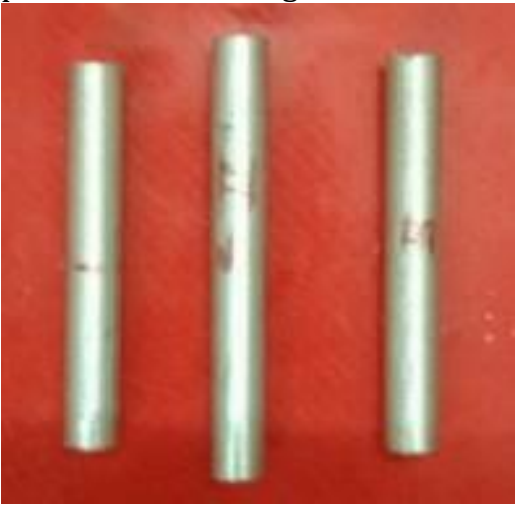

Fig 3.2(a)Wear specimen
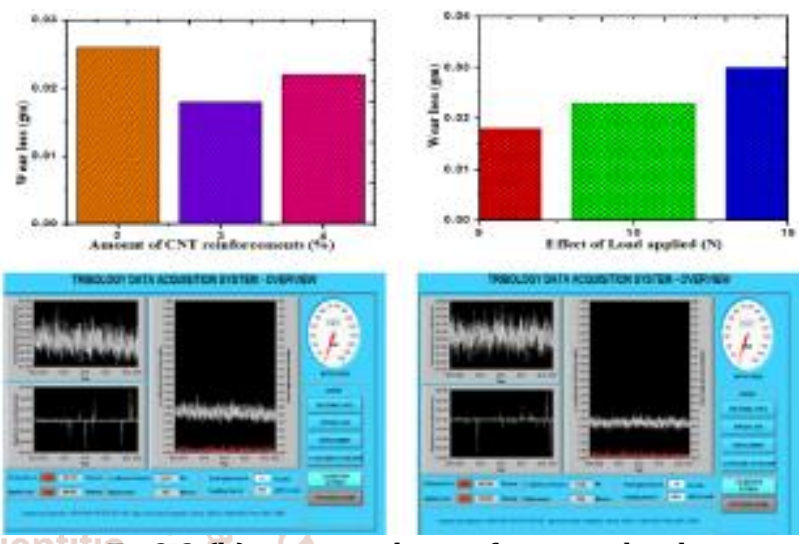

Fig3.2 (b) wear analysis of various load

\subsection{Metallurgical test}

To ensure the proper dissemination of the reinforcement in the matrix in order to identify its homogeneity, the microstructural characterization was studied by using advanced optical microscopy. The specimens are mechanically polished with the help of automatic disc polishing machine. And then, the specimen was positioned on the observing stage of the microscope (MEIJIJAPAN/MIL-7100). Then the microstructure is examined and photographs of microstructure were taken at different magnification to understand the grain boundaries and the corresponding grain structures. The dry sliding wear surface has been analyzed with the help of SEM and FE-SEM to understand the surface morphology of MMC after wear loss in the composites.

In order to ensure the presence of elements inside the MMC, Energy Dispersive X-ray Analysis (EDAX) was carried out. Also, to understand the energy level of the composites, AFM study has been performed. Finally, the Transmission electron Microscopy (TEM) measurements were carried out for the MMCs for which the samples (powder form) were repaired using ion milling and then viewed at $0.27 \mathrm{~nm}$ point resolution at an accelerating voltage of $200 \mathrm{KV}$ and at an exposure time of $15 \mathrm{~s}$ and observed through the high magnification microscope (Make: FEI - NETHERLANDS, Tecnai 20 G2).

\subsection{Tensile and micro hardness analysis}

The mechanical test results show that the strength, toughness and hardness of MMCs are greater than the parent metal .It show that the mechanical properties have been 
increased with the increase in volume percentage of MWCNT particulates. The Metal Matrix composite (MMC-1) produced with the reinforcement of MWCNT $(2 \%)$ average results shows that there has been $13 \%$ increase of microhardness and $10 \%$ increase of tensile strength from its base metal. The MMC-2 produced with the reinforcement of MWCNT (3\%) average results shows that there has been $21 \%$ increase of microhardness and $14 \%$ increase of tensile strength from its base metal, and the Metal Matrix Composite (MMC-3) produced with the reinforcement of MWCNT (4\%) average results shows that there has been $30 \%$ increase of microhardness and $12 \%$ increase of tensile strength from its base metal. The formation of coarse intermetallic compounds during consolidation and subsequent processing will reduce the tensile properties of the composite. In this research work, due to the controlled temperature distribution during the adding of CNT nanoparticle in to the liquid state molten metal, the formation

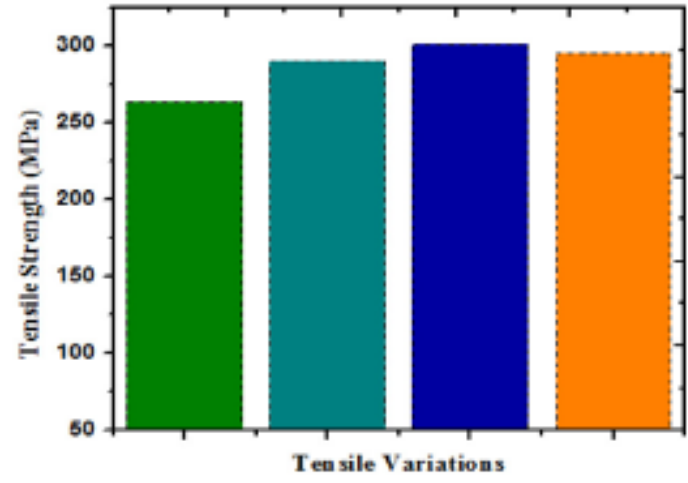

Fig.3.4 (a) graphical representation of tensile load variations

The variation in load helps to understand the loss of material during metal to metal contact between its interfaces at higher loads. As reported by figure below, the percentage of wear loss reduces when the percentage of reinforcement to the monolithic metal increases. At $20 \mathrm{~N}$ force of applied load, the material undergoes more wear due to the forging pressure and friction increasing between two worn surfaces of the metal.

\subsection{Metallurgical analysis}

The microstructural features of the composites are analyzed in order to confirm the dissemination of the reinforcement in the matrix. The excellent features of microstructures are relatively lower porosity in the casting which is an important aspect in cast metal matrix composites. The optical micrographs of nanocomposites show the dendritic cast structure consisting of CNT particles in a eutectic matrix than the unreinforced magnesium alloy and increasingly refined microstructural features from the observation.

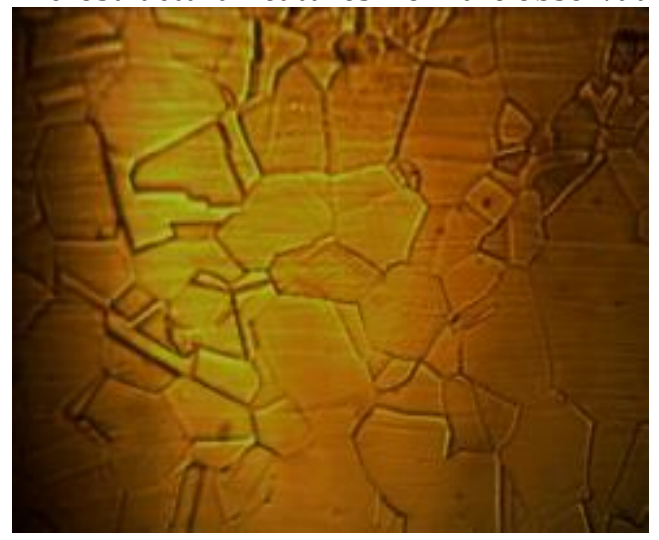

Fig3.5 (a) basemetal

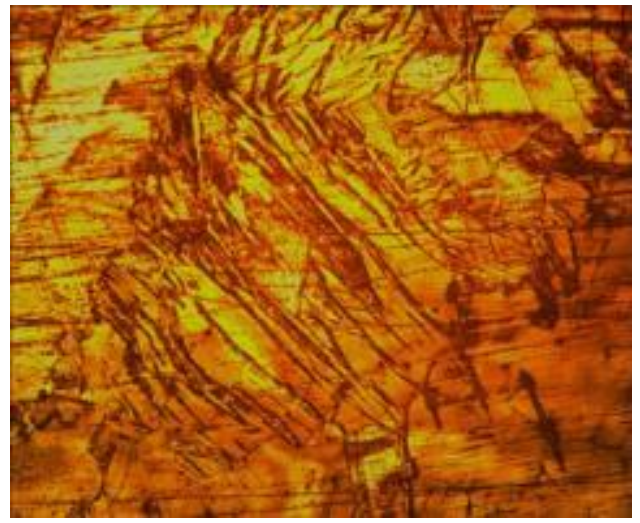

Fig 3.5(b) mmnc1 (2\% cnt)

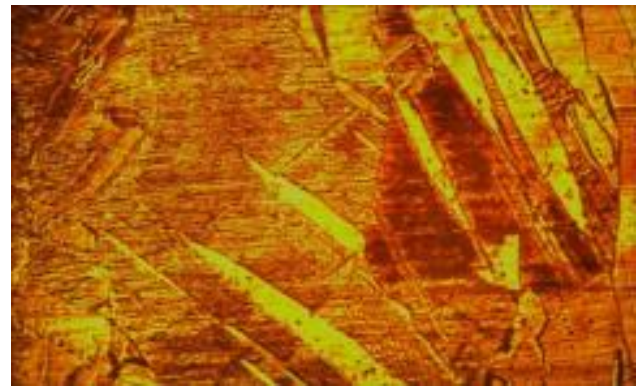

Fig 3.5(c) mmnc 2 (3\% cnt)

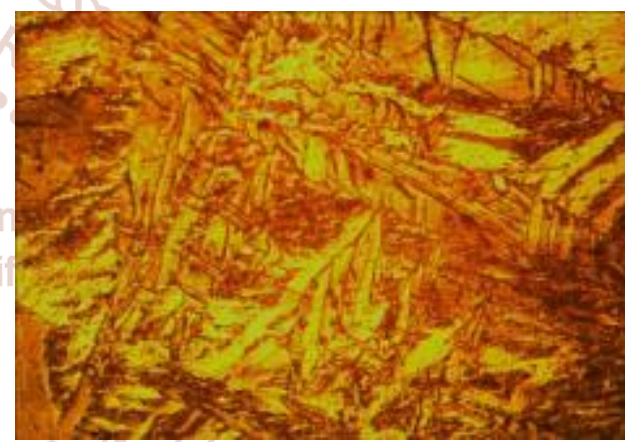

Fig 3.5(d) mmnc 3 (4\% cnt)

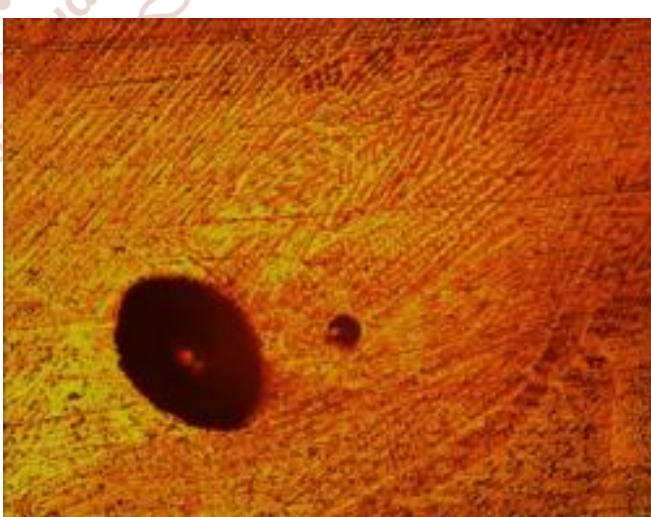

Fig 3.5(e) Initial defects in MMNC

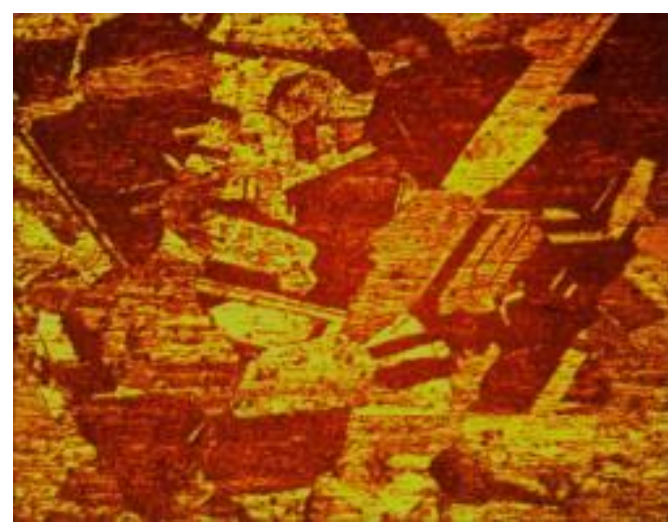

Fig 3.5(f) Inhomogeneous mix 
The figure (b-d) represents the optical microscopic view of the stir casted CNT reinforced magnesium MMC which shows that the distribution of articulates are relatively homogenous and are without any defects. Fig 5(a) shows the optical micrograph of the parent metal. The porous occurred during fabricating the composites are also displayed in fig.5(e-f) respectively.

\subsection{Worn and impact surface morphology analysis by SEM and FE-SEM}

The SEM and FE-SEM analysis for the fabricated composites were analyzed to understand the mode of failure occurred in the produced composites and it is displayed in the figure below. It can be understood that the abrasion and delamination are commonly observed in the wear sample as reported by Gurcan et al. [15]. The MMC 1 sample exhibits brittle mode fracture due to the reduced fracture toughness. The MMC 2 sample shows ductile mode of fracture due to the increased tensile strength. Measurement of the bond strength on the basis of ductile fracture involves establishing the local stress state during plastic deformation and Agitation during processing is necessary to disrupt contamination films and adsorbed layers to enable interfacial bonding. The produced nano composite was examined for voids, fissures and separation between CNTMg matrix with help of SEM and it was confirmed that there is no voids and separation in the nanocomposite. Therefore, a strong bond and excellent "wetting" between the matrix and the reinforcement is achieved by utilizing correct processing temperatures $\left(\mathrm{T}>700^{\circ} \mathrm{C}\right)$ and other parameters. The drawbacks of melt infiltration process include reinforcement damage, microstructural non-uniformity, preform compression, coarse grain size, interaction between reinforcement and matrix are negligible in the MMNC which is confirmed by mechanical and metallurgical testing.

The basic three factors that lead to a brittle and cleavage mode of fracture are (i) a high strain rate or rapid rate of loading (ii) a low temperature and, (iii) the tri axial state of stress. All of the above mentioned factors need not to exist spontaneously to induce brittle fracture in composite. Many types of impact tests were used to determine the exposure of materials to brittle cleavage behaviour and therefore at a high loading rate, these effects are emphasized. The standard Charpy V-notch sample is thick enough to confirm a high degree of plane strain loading and triaxiality across almost all of the notched cross section and it also provides a test for cleavage and brittle fracture (Rolfe and Barsom) [17] evidently it is also obtained in the produced MMC. The key measurement from the toughness test is the energy absorbed in fracturing the specimen.

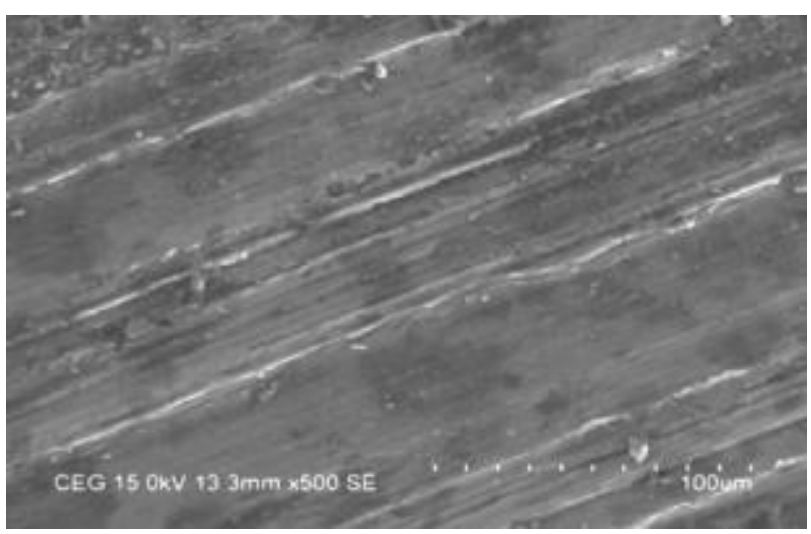

Fig 3.6(a).Deformed layer

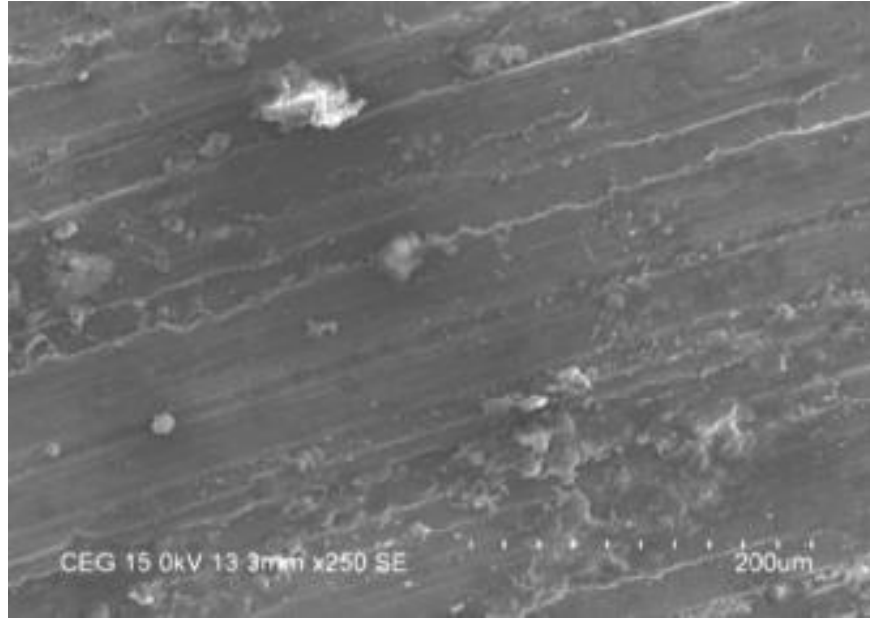

Fig 3.6(b).wear debris

\section{Conclusion}

Based on the above investigation, the conclusions have been given

1. The metal matrix composite comprising of Mg+ CNT $4 \%$ exhibits higher hardness than the base metal and composite and Mg + CNT 3\% exhibits the higher tensile strength and impact toughness than the other composites.

2. The MMC with CNT 3\% shows better wear properties compared to the base metal properties and it shows ductile mode of fracture due to the increased tensile strength than the other composites.

3. The optical micrographs of metal matrix composites show the dendritic cast structure consisting of CNT particles in a eutectic matrix than the unreinforced

cic magnesium alloy with less porosity.

4. The tensile strength and hardness of MMC are having directly proportional relationship with percentage of MWCNT particulate into the Mg AZ91D grade magnesium alloy metal matrix nanocomposite.

\section{References}

[1] M.M. Avedesian, H. Baker, Magnesium and Magnesium Alloys, ASM International, Materials Park, 1999.

[2] King, Proceedings of the 60th Annual World Magnesium Conference. The International Magnesium Association, Wauconda, IL, USA, 10-16.

[3] D.B. Miracle, Compos. Sci. Technol. 65 (2005) 25262540 .

[4] A. M. S. Hamouda, S. Sulaiman, T.R. Vijayaram, M. Sayuti, M.H.M. Ahmad, J. Achieve. Mater. Mfu. Eng. 25 (2007) 1-16.

[5] J. Hashim, L. Looney, M.S.J. Hashmi, J. Mater. Process. Technol. 119 (2001) 329-335.

[6] K. Dash, Mater. Res. Bull. 48 (2013) 2535-2542.

[7] S. Mula, P. Padhi, S.C. Panigrahi, S.K. Pabi, S. Ghosh, Mater. Res. Bull 44 (2009) 1154- 1160.

[8] R. N. Ahmed, C.S. Ramesh, Int. Symp. Res. Mater. Sci. Eng. India (2004) 20-22.

[9] S. R. Bakshi, D. Lahiri, A. Agarwal, Int. Mater. Rev. 55 (2010) 41-64.

[10] K. Soorya Prakash, P. Balasundar, S. Nagaraja, P.M. Gopal, V. Kaviman. Magnes. Alloys 4 (2016) 197-206. 
International Journal of Trend in Scientific Research and Development (IJTSRD) @ www.ijtsrd.com eISSN: 2456-6470

[11] S. Basavarajappa, G. Chandramohan, K. Mukund, M. Ashwin, M. Prabu, J. Mater. Eng. Perform. 15 (2006) 668.

[12] A. A. Luo, J. Magnes. Alloys 1 (2013) 2-22.

[13] E.-S.M. Sherif, F.H. Latief, H. Junaedi, A.A. Almajid, Int. J. Elechem. Sci. 7 (2012) 4352-4361.

[14] G. Straffelini, M. Pellizzari, A. Molinari, Wear 256 (2004) 754-763.

[15] A. B. Gurcan, T.N. Baker, Wear 188 (1995) 185-191.

[16] A. R. Riahi, A.T. Alpas, Wear 251 (2001) 1396-1407.

[17] S. T. Rolfe, J.M. Barsom, Eng. J. Am. Inst. Steel Construct. (1977) 1-15.
[18] J. Goldstein, D. Newbury, D. Joy, C. Lyman, P. Echlin, E. Lifshin, et al., Scanning Electron Microscopy and X-Ray Microanalysis, Springer, 2013, doi:10.1007/978-14615-0215-9.

[19] S. Sinha Ray, K. Okamoto, M. Okamoto, Macromolecules 36 (2003) 2355-2367.

[20] A. Ranade, N.A. D’Souza, B. Gnade, Polymer (Guildf.) 43 (2002) 3759.

[21] M. Okamoto, S. Morita, Y.H. Kim, T. Kotaka, H. Tateyama, Polymer (Guildf.) 41 (2000) 3887-3990.

[22] O. Monticelli, Z. Musina, S. Russo, S. Bals, Mater. Lett. 61 (2007) 3446-3450. 